\title{
More humorous employees, more eager to innovate: psychological capital explained
}

\author{
Indah Suciati $^{1 *}$, Alice Salendu ${ }^{1}$, and Eka Gatari ${ }^{1}$ \\ ${ }^{1}$ Faculty of Psychology, Universitas Indonesia, Kampus UI Depok, Depok 16424, Indonesia
}

\begin{abstract}
Previous studies show that researchers are interested in studying the relationship of humour with creativity and innovation. Using the broaden-and-build theory, the present study explores the relationship between humour and innovative work behaviour then explain its process by the mediating role of psychological capital. 172 employees participated in this study through a self-report questionnaire. The result shows that psychological capital fully mediates the relationship between humour and innovative work behaviour. The theoretical and practical implications of the findings are discussed along with the future research direction.
\end{abstract}

\section{Introduction}

In this dynamic and fiercer business world competition, companies are required not only to adapt to progressive changes but also to take initiatives to bring up and implement new ideas. Thus, innovation is needed to tackle those challenges, and simultaneously, it is one of important parts to support industrialization as stated in Sustainable Development Goal (SDG) number 9 [1]. In order to support achieving SDG 9, companies need to be manned by supportive human resources, which can be called as innovative forces. Therefore, the employees' innovative behaviour, or Innovative Work Behaviour (IWB), is an important behaviour to be studied. Janssen [2] define IWB as "the intentional creation, introduction, and application of new ideas within a work role, group or organization, in order to benefit role performance, the group, or the organization" (p. 288) based on West and Farr [3].

Janssen [2] further explained that there are three stages in IWB include idea generation (generating new and useful ideas based on the conditions and problems they are facing), idea promotion (finding a partner or group that has the same view or convincing the necessary parties about the idea benefits), and idea realization (realizing the ideas into reality in the form of prototypes and direct applications). Many factors influence IWB, such as individual differences, job characteristics, and company's contextual factors [4]. Of these factors, the individual differences or internal characteristics is considered to be the main factor causing the emergence of innovative behaviour [3]. Therefore, this research will discuss more on the individual factors. At the individual level, one factor that influences the IWB and still needs to be explored is humour, since there is still a need to understand the process how humour can influence IWB.

\footnotetext{
*Corresponding author: indah.suciati61@ui.ac.id
} 
Humour is "...habitual individual differences in all sorts of behaviours, experiences, affects, attitudes, and abilities relating to amusement, laughter, jocularity, and so on" (p. 17) [8]. From this definition, we can say that humour is often intended to make others laugh so that it can bring a more pleasant atmosphere. Individuals who like to make jokes so that others laugh are often seen as having good intelligence and are sensitive to the conditions and feelings of their colleagues [9]. The sensitivity of humorous employees about the surrounding conditions, accompanied by their good intelligence, can help bringing new ideas.

Additionally, there are differences in the types of humour that employees have with others. There are four types of humour: affiliative, self-enhancing (positive form), aggressive, and self-defeating (negative form) [10]. This study will focus more on positive humour styles because it can promote positive emotions without offending others. This focus is different from the negative ones, such as the aggressive humour which tends to bring sarcastic jokes or hostile to others, and the self-defeating humour which seems to underestimate others [10]. In addition, from previous studies, it has been proved that self-enhancing [11] and affiliative humour [12] are positively related to IWB, while the aggressive and self-defeating ones are not significantly related.

Moreover, two studies that have examined the humour relations with IWB $[13,12]$ showed that the effect size of humour relationships with IWB is .32 and .29 respectively, in which is classified as a low effect size $(<.50)$ [14]. Therefore, in this study, we propose a mediator to explain the relationship between humour and IWB, that is, psychological capital. Psychological capital is taken as a mediator because it is related to positive things both at the individual and organizational level [15]. Furthermore, Srivastava and Maurya [15], also stated in their conceptual model that humour is related to the psychological capital, and psychological capital is related to IWB.

In the process, we use the broaden-and-build theory [18] to explain the logical flow of the model in this study. This theory states that the individuals who are in a positive state of mind have greater ability to expand their perspective in thinking [18]. The jokes that are expressed by humorous individuals can make themselves laugh and build an positive state of mind [19]. Therefore, the humorous individuals can demonstrate IWB because they can think with a broad perspective to generate new ideas.

Furthermore, humorous individuals can reduce their negative views when they are failing or having problems because they are protected from stress by their humour [19]. Thus, humorous individuals will be more confident and consider the problem they face as a challenge (self-efficacy). As Bandura [16] stated, individual with high self-efficacy are more likely to perceive that they are capable to carry out their task and ready to undertake a risky and challenging activity, such as creative/innovative work. Through this confidence, they can bring up innovative ideas as a form of their efforts to solve the challenging conditions they are facing during their work. Humorous individuals can also laugh even when they have problems or constraints [10]. This makes them have better hope and optimism, so they will still be able to easily rise again from their failures (resilience). The optimism that individuals have will encourage them to generate creative ideas and implement them well. In implementing creative ideas in the company, there may be problems that they encountered, but humorous individuals are still motivated to apply their ideas because they see much hope and they are resilient to face the challenges that arise from their problems.

In general, humorous individuals are more positive in dealing with problems so that their psychological condition is also positive. This will improve their psychological capital, which then encourages them to utilize their broad ways of thinking to produce innovation. Therefore, the hypothesis in this study is "Psychological capital mediates the relationship between the humour and IWB". 


\section{Methods}

The participants in this study are the employees of companies that have the vision, mission, values or competencies that relate to innovation. The employees can become the participants if they have worked for at least one year at their current company. The participants are chosen non-randomly using convenience technique.

This is a quantitative research conducted using survey method using Hayes' PROCESS MACRO technique to analyse the data. In collecting the data, the questionnaire used also contained other variables to test other research models. The data collection uses online and offline questionnaires that is carried out in two data retrieval periods from 1-2 weeks. The first is the data collection for humour style and psychological capital, then followed with IWB.

The data collection is done twice to reduce common method biases that might appear [20]. During the first data collection, 357 employees participate in this study. However, in the second data collection, there are only 225 employees that participate in this study. Then, the participants who do not meet the criteria and outlier data are put aside, so that there are 172 employees (70 offline and 102 online) whose data are processed in this study. The study participants consist of 85 females and 87 males. The participants come from staff to senior manager level, with the staffs as the majority $(48.3 \%)$.

To measure IWB, we use the adaptation version of Innovative Work Behaviour Scale from Janssen [2] by Etikariena and Muluk [21]. The questionnaire consists of nine items with responses range between 1-6 (never - always). Cronbach's Alpha of this scale is .95

The measurement of psychological capital is carried out using an adapted scale of the PCQ-12 [22]. PCQ-12 consists of 12 statements representing four dimensions, namely selfefficacy (three statements), hope (four statements), resilience (three statements), and optimism (two statements) with response choices ranging 1 for strongly disagree, to 6 to strongly agree. The reliability (Cronbach's Alpha) of this scale is .86.

The humour is measured using the instruments adopted from Lussier, Grégoire, and Vachon [23] (with the range of $1=$ strongly disagree to $6=$ strongly agree). Cronbach's Alpha of this questionnaire is .86 .

\section{Results}

Table 1. Correlation matrix among variables.

\begin{tabular}{llccccccr}
\hline \multicolumn{1}{c}{ Variables } & M & SD & $\mathbf{1}$ & $\mathbf{2}$ & $\mathbf{3}$ & $\mathbf{4}$ & $\mathbf{5}$ \\
\hline 1 & Humour & 17.68 & 3.22 & -.015 & -.07 & - & & \\
2 & IWB & 30.16 & 9.45 & $.25^{* *}$ & .12 & $.22^{* *}$ & - & \\
3 & Psychological capital & 52.05 & 7.18 & .04 & .12 & $.25^{* *}$ & $.46^{* *}$ & - \\
\hline
\end{tabular}

Note. $\mathrm{N}=172$, all scales were measured on a 6-point scale. ${ }^{* *}$ Significant at the .01 level (2-tailed), IWB = innovative work behaviour

Table 1 shows that humour is positively related to IWB $(\mathrm{r}=.25, \mathrm{p}<.01)$. This means that the more humorous employee is, the more likely he/she will be to show his/her IWB. Humour is also positively related to psychological capital $(\mathrm{r}=.25, \mathrm{p}<.01)$, so it can be stated that the more humorous employees, the higher their psychological capital. In addition, psychological capital is positively related to IWB $(r=.46, \mathrm{p}<.01)$. 
Table 2. Mediating effect of psychological capital in the relationship between humour and IWB.

\begin{tabular}{|c|c|c|c|c|c|c|}
\hline & \multicolumn{6}{|c|}{ Outcome Variables } \\
\hline & \multicolumn{3}{|c|}{ Psychological Capital } & \multicolumn{3}{|c|}{ Innovative Work Behaviour } \\
\hline & $\mathrm{B}$ & $\mathrm{SE}$ & $t$ & $\mathrm{~B}$ & $\mathrm{SE}$ & $t$ \\
\hline $\begin{array}{l}\text { Psychological } \\
\text { Capital }\end{array}$ & - & - & - & $.57 * *$ & .09 & 6.22 \\
\hline Humour & $.55 * *$ & .17 & 3.32 & .33 & .20 & 1.61 \\
\hline
\end{tabular}

Note. $\mathrm{N}=172, * *$ significant at the .01 level (2-tailed), Analysis using Bootstrap 5000

Using simple mediation analysis, the results are shown in Table 2. Humour is indirectly related to IWB through how much psychological capital employees have. The analysis shows that the more humorous employees, the higher their psychological capital $(\alpha=.55, \mathrm{p}<.01)$ and the higher their psychological capital, the higher their tendency to display IWB $(b=.57$, $\mathrm{p}<.01)$. Furthermore, there is no evidence to suggest that humour is directly related to IWB $\left(c^{\prime}=.33, p>.01\right)$. Next, the total effect, direct effect, and indirect effect can be seen in Table 3 .

Table 3. Total effect, direct effect, and indirect effect analysis on the relationship between humour and IWB.

\begin{tabular}{cccc}
\hline \multicolumn{4}{l}{ Total effect of Humour on Innovative Work Behaviour } \\
\hline $\mathrm{B}$ & $\mathrm{SE}$ & $T$ & $P$ \\
\hline .64 & .22 & 2.94 & .00 \\
\hline \multicolumn{2}{l}{ Direct effect of Humour on Innovative Work Behaviour } & $P$ \\
\hline $\mathrm{B}$ & $\mathrm{SE}$ & $T$ & .11 \\
\hline .33 & .20 & 1.61 & \\
\hline Indirect effect (s) of Humour on Innovative Work Behaviour & BootULCI \\
\hline $\mathrm{B}$ & BootSE & BootLLCI & .58 \\
\hline .31 & .12 & .09 &
\end{tabular}

Based on the indirect effect analysis, it is shown that there are significant indirect effects in the relationship between the humour and IWB through psychological capital $(\alpha b=.31$, BootLLCI $=.09$, and BootULCI $=.58$ ). Thus, the hypothesis in this study is accepted, that the psychological capital fully mediates the humour with IWB.

\section{Discussion and conclusion}

This study found that humour is not directly related to IWB, but their relationship is explained through psychological capital. This research contributes to the new findings regarding the role psychological capital as the explanation of how humour can improve IWB. Humour is one of the responses to be able to adapt to face problems [19], which can help them build their psychological capital. The psychological capital owned by the employees then helps them to perform their IWB because they can see problems more positively and also resilient and confident in times of trouble. This positive mindset will also help them to generate ideas better and apply their innovativeness.

However, this study also still has some limitations. First, because the data collection is done in two stages, there are many unused data from the participants of the first stage. This is due to only about $63 \%$ of participants in the stage one is participating again in the second stage of the data collection. Therefore, other methods need to be done to reduce one of the common methods bias without losing a large amount of participants. For example, by 
measuring through peer rating, where other people respond using their perceptions of the participants.

Second, this study does not control other variables that might influence the employees to perform IWB. The first variable that needs to be controlled, for example, is the leadership style. Leadership style is an important thing that can affect the employees in the innovation process [5]. Leader has a role to create an atmosphere that can help the employees balance between carrying out daily works and the activities that can facilitate the innovation process [5].

In addition, to strengthen the theory that humour affect IWB through psychological capital in the long term, longitudinal research should be carried out. A long-term research needs to be done because basically innovation is an ongoing process from generating ideas to their implementation that certainly takes time [2], and on its way, the innovation process may be influenced by other factors. Therefore, further research is needed to study the innovation longitudinally that aims to test whether the dynamics between the three variables in this study are quite stable over time or if there are other factors influence them.

Based on the data analysis, it can be concluded that psychological capital mediates the humour and the IWB. Through this empirical evidence, it can be said that individual factors are one of the factors that can support the existence of IWB within the employees. This research provides some implications. Theoretically, this research contributes to explain the mechanism of the relationship between the humour and IWB of the employees through the psychological capital. Then practically, this research can also be used by the companies as the basis to promote IWB, which hopefully can boost the effort to achieve SDG 9. Companies should consider the self-capacity of the employees to be able to stimulate creative ideas, in this case, humour and psychological capital. Therefore, the companies can facilitate them by considering some conditions such as giving them time to channel appropriate jokes that can melt the tense atmosphere during a meeting but not distract the members of the meeting to meet their goals. Additionally, by this result, company can consider boosting employees' positive humour in order to promote IWB. Some programs that can be used as references are a program from McGhee [24] or by conducting systematic program as done by Nevo, Aharonson, and Klingman [25].

\section{Acknowledgement}

The authors gratefully acknowledge that this research is funded by PITTA UI grant year 2018.

\section{References}

1. UN. Retrieved from https://www.un.org/sustainabledevelopment/infrastructureindustrialization/ (n.d)

2. O. Janssen, J. Occup. Organ. Psychol. 73, 3, 287-302 (2000)

3. M. A. West, J. L. Farr, Social Behaviour 4, 15-30 (1998)

4. M. M. Hammond, N. L. Neff, J. L. Farr, A. R. Schwall, X. Zhao, Psychol. Aesthet. Creat. Art 5, 1, 90-105 (2001)

5. N. Anderson, K. Potočnik, J. Zhou, J. Manag. 40, 5, 1297-1333 (2014)

6. S. A. Woods, M. J. Mustafa, N. Anderson, B. Sayer, J. Manag. Psychol. 33, 1, 29-42 (2017)

7. M. Li, Y. Liu, L. Liu, Z. Wang, Curr. Psychol. 36, 697-706 (2017)

8. R. Martin, Approaches to the sense of humour: A historical review. In W. Ruch (Ed.), The Sense of Humour: Explorations of A Personality Characteristic (Mouton de Gruyter, 
New York, 1998)

9. S. Shellenbarger, Retrieved from https://www.wsj.com/articles/the-joke-that-makes-orbreaks-you-at-work-1485273069 (2017)

10. R. A. Martin, P. Puhlik-Doris, G. Larsen, J. Gray, K. Weir, J. Res. Pers. 37, 48-75 (2003)

11. S.

Balazs-McCord,

Retrieved

from https://search.proquest.com/docview/1953259491?accountid=17242 (2017)

12. C. Promsri, Int. J. Acad. Res. Bus. Soc. Sci. 7, 9, 342-351 (2017)

13. P. Hurmelinna-Laukkanen, K. Atta-Owusu, E. L. Oikarinen, ISPIM Conference Proceedings, Retrieved from https://search.proquest.com/openview/da3f7ae4b655e1d85e5fb66d66138fb1/1?pqorigsite $=$ gscholar\&cbl $=1796422$ (2016)

14. J. Cohen, Statistical Power Analysis for the Behavioural Sciences. Routledge Academic (second ed.) (Lawrence Erlbaum Associates, United States of America, 1988)

15. U. R. Srivastava, V. Maurya, Labour stud. 42, 3, 205-236 (2017)

16. A. Bandura, Self-Efficacy. In V. S. Ramachandran (Ed.), Encyclopedia of Human Behaviour (Academic Press, New York, 1998)

17. D. Sweetman, F. Luthans, J. B. Avey, B. C. Luthaans, Can. J. Adm. Sci. 28, 1, 4-13 (2011)

18. B. L. Fredrickson, Am. Psychol. 56, 3, 218-226 (2001)

19. H. M. Lefcourt, Humour. In C. R. Snyder \& S. J. Lopez (Eds.), Handbook of Positive Psychology (Oxford University Press, New York, 2002)

20. P. M. Podsakoff, S. B. MacKenzie, J. Y. Lee, N. P. Podsakoff, J. Appl. Psychol. 88, 5, 879-903 (2003)

21. A. Etikariena, H. Muluk, Makara Hubs-Asia, 18, 2, 77-88 (2014)

22. J. B. Avey, B. J. Avolio, F. Luthans, Leadersh. Q. 22, 282-294 (2011)

23. B. Lussier, Y. Grégoire, M. Vachon, Industrial Marketing Management 1-14 (2017)

24. P. E. McGhee, How to Develop Your Sense of Humor (Kendal and Hunt, Dubuque, IA, 1994)

25. O. Nevo, H. Aharonson, A. Klingman, The development and evaluation of a systematic program for improving sense of humor. In W. Ruch (Ed.), The Sense of Humor: Explorations of A Personality Characteristic (Mouton de Gruyter, New York, 1998) 